九州大学学術情報リポジトリ

Kyushu University Institutional Repository

\title{
A Study of the Leaf Phenology and Thermonastic Leaf Movement of Daphniphyllum macropodum
}

Park, Seok-Gon

Division of Forest Resources and Landscape Architecture, Sunchon Univ. I Institute of Tropical Agriculture, Kyushu University

Matsumoto, Masaru

Institute of Tropical Agriculture, Kyushu University

https://doi.org/10.5109/1833813

出版情報：九州大学大学院農学研究院紀要. 62 (2)，pp.329-335，2017-09-08. Faculty of Agriculture, Kyushu University

バージョン :

権利関係 : 


\title{
A Study of the Leaf Phenology and Thermonastic Leaf Movement of Daphniphyllum macropodum
}

\author{
Seok-Gon PARK ${ }^{1,2}$ and Masaru MATSUMOTO ${ }^{2}$ \\ Institute of Tropical Agriculture, Kyushu University, Hakozaki, 6-10-1, Fukuoka 812-8581, Japan \\ (Received April 24, 2017 and accepted May 10, 2017)
}

\begin{abstract}
In this study, leaf phenology (the seasonal growth pattern of leaves) was investigated for 1 year to investigate the life-cycle strategies of Daphniphyllum macropodum. In addition, the degree of drooping and rolling of the leaves was measured at freezing temperatures in the winter, and the leaf moisture and leaf thickness were examined to determine the changes within the leaves. In April, young leaves unfolded in a flush, while the leaves that had emerged the previous year began to fall. The leaf longevity of $D$. macropodum was 12-17 months, and in spring, leaf unfolding and defoliation occurred almost simultaneously, avoiding self-shading. The leaves of $D$. macropodum are thick and wide; thus, old leaves block the light from young leaves, reducing their photosynthesis rate. Therefore, it is assumed that there is no need to keep old leaves on the branch for a long time.

The phenomena of drooping and rolling were easily observed in the leaves of $D$. macropodum at $-6.9^{\circ} \mathrm{C}$, which disappeared at $-3.6^{\circ} \mathrm{C}$. There was no change in the moisture content of the leaves with the changes in the freezing temperature (below $0^{\circ} \mathrm{C}$ ), but the leaf thickness decreased with the decreasing freezing temperature. This phenomenon is called thermonastic leaf movement, which may be a reaction to the freezing temperature in order to prevent excessive moisture loss in winter. It appears that at the freezing temperature, the water inside the cells migrates out of the cell and gathers together, resulting in a change in the leaf thickness.
\end{abstract}

Key words: Carbon economy, Freezing temperature, Leaf longevity, Leaf rolling, Self-shading

\section{INTRODUCTION}

Daphniphyllum macropodum is an evergreen broad-leaved species, distributed in subtropical zones and warm-temperate zones, such as south central China, the southern area of Honshu in Japan, Taiwan and Vietnam. On the Korean peninsula, D. macropodum grows wild mainly in the warm-temperature evergreen broad-leaved forests of Jeju Island, Ulleungdo and islands in the Jeonbuk and Jeonnam provinces (Park et al., 2015). D. macropodum is distributed in the understory layer or the shrub layer of evergreen broad-leaved forests and grows at a slow rate in a weak-light environment. Species that grow in the shaded floor of evergreen broad-leaved forests are generally characterized by low light saturation, thick leaves and long leaf longevity (Kikuzawa, 2005). The common Japanese name of $D$. macropodum is Yuzuri-Ha Tree, which originated from the meaning that when young leaves emerge in spring, the leaves from the last year yield. Although the leaves of $D$. macropodum are evergreen, their longevity is short, similar to deciduous broad-leaved trees. Because this small tree has different leaf longevity patterns and characteristics compared with ordinary evergreen broad-leaved species, the tree's life-cycle strategies are expected to be different. As the leaf is an organ specialized to obtain carbon in the atmosphere, to acquire the maximum amount of carbon, the tree's leaf longevity is

\footnotetext{
Division of Forest Resources and Landscape Architecture, Sunchon Univ., Sunchoen (57922), Korea.

Institute of Tropical Agriculture, Kyushu University

* Corresponding author (E-mail: eco-research@hanmail.net)
}

determined. Therefore, studies on leaf longevity and leaf phenology (the seasonal growth pattern of leaves) will be useful in understanding the life-cycle strategies of $D$. macropodum (Kikuzawa, 1989).

Meanwhile, the natural habitat of $D$. macropodum in the Naejangsan National Park, which is located in the temperate region of Korea, has been designated a natural monument. This area is a northern region in which D. macropodum can grow wild, where the growth conditions are poor for evergreen broad-leaved species with a daily minimum temperature of $-16.3^{\circ} \mathrm{C}$ in winter (Korea Meteorological Agency data). It is believed that the reason these trees can withstand such environmental conditions is related to the rolling and drooping phenomenon of $D$. macropodum leaves at freezing temperatures in winter. One of the most prominent plants showing this phenomenon is Rhododendron. Scholars pointed out more than a hundred years ago that the leaves of Rhododendron roll at freezing temperatures (Nilsen et al., 2014). This phenomenon is called thermonastic leaf movement, which has been closely associated with the cold-resistant property of Rhododendron (Nilsen and Tolbert, 1993). Rolling and drooping occur when the leaves reach the wilting point. These phenomena occur when the turgor pressure in the cell decreases due to the cell's reduced water content, which can be restored to the original state by the water supply. Drooping and rolling occur in Rhododendron leaves at temperatures below -2 to $-5^{\circ} \mathrm{C}$, when the temperature is a few degrees lower than the freezing point of the leaf within 10 to 20 minutes regardless of radiation (Fukuda, 1932; Nilsen, 1985; 1987). The lower the temperature, the more intensely these phenomena appear (Fukuda, 1932, 
Nilsen, 1987). Rolling during the summer is caused by moisture stress, but the maximum rolling at the wilting point is only $30-45 \%$ of that induced by cold. Thus, rolling is only partially dependent on the low water potential of the leaf (Nilsen, 1987). Thermonastic leaf movement has a different mechanism from dehydration of leaves that occurs at the wilting point (Nilsen et al., 2014). Nilsen et al. (2014) discussed the mechanistic and functional significance of thermonastic leaf movement in Rhododendron in depth. However, there has been a lack of research on and discussion about whether the drooping and rolling of $D$. macropodum leaves in the winter are a type of thermonastic leaf movement.

Therefore, in this study, we investigated the leaf number, leaf area, leaf thickness, leaf mass per area, shoot length and changes in the chlorophyll content of leaves in $D$. macropodum for 1 year to investigate the tree's life-cycle strategies. In addition, the degrees of drooping and rolling were measured at freezing temperatures in winter, and the leaf moisture content and leaf thickness were examined to determine the changes within the leaves.

\section{MATERIALS AND METHODS}

\section{Research site overview and plant materials}

The research site was the campus and a farm of Sunchon University located in Suncheon city, Jeollanamdo, South Korea. Four D. macropodum trees planted there were selected as the test materials. Three of the trees were planted at the back of a five-story building facing south (about $16 \mathrm{~m}$ high) on the Sunchon University campus. The remaining tree was located in front of a south-facing building on the farm. As a result, the relative photosynthetic photon flux density (PPFD) of the D. macropodum trees on the campus was dark at 15.3$40.5 \%$. However, the relative PPFD of the D. macropodum tree on the farm was comparatively brighter at $83.2 \%$. These D. macropodum trees were about 2.7$7.5 \mathrm{~m}$ tall, and their growth condition was good (Table 1).

\section{Research and analytical methods}

To identify the leaf phenology of $D$. macropodum, the leaf number, leaf area, chlorophyll content, leaf thickness and shoot length were investigated. For the num- ber of leaves, new leaves that emerged during the current year (young leaves) and old leaves that had emerged the previous year (1-year-old leaves) on a branch were counted separately. Six branches (a total of 24 branches) were picked from each of the four D. macropodum trees, and each leaf was marked with an index card to track it. New leaves of $D$. macropodum often emerge in early April, and most of the old leaves fall at this point. Because no changes in the leaves are expected in winter, the examinations were carried out once a month from the end of February 2014 to the end of October 2014. To measure the surface area of the $D$. macropodum trees, 80 leaves were collected and scanned with an ordinary scanner. The leaf area was calculated using a leaf area measurement program (LIA32, ver.0.376 $\beta 1$ ), and the long axis and the short axis of each leaf were measured. Then, the relationship of the ellipse area, which was calculated based on the leaf area and the long and short axes of the leaf, was shown as a regression equation. Using this equation, the area of one leaf of a $D$. macropodum tree during each period was estimated. A total of 240 leaves were examined to determine the leaf area by measuring 60 leaves per tree. The chlorophyll content and the leaf thickness were measured using the same leaf that was used to measure the leaf area. For the chlorophyll content, the SPAD value was measured with a MINOLTA (SPAD-502, Japan) Chlorophyll Meter, and the leaf thickness was measured with a digital micrometer (Mitutoya 293-821). For the shoot length, the length of the new branches that emerged during the current year was measured.

When the temperature dropped below freezing, drooping and rolling occurred in the leaves of $D$. macropodum as in Rhododendron. These phenomena appear to be an adaptive response to the freezing temperature. In order for the leaves of $D$. macropodum to react, changes in the leaf moisture content and leaf structure must occur. Therefore, the degrees of rolling and drooping, leaf moisture content $\left(\mathrm{g} / \mathrm{cm}^{2}\right)$ per area, leaf mass per area (LMA, $\mathrm{g} / \mathrm{m}^{2}$ ) and leaf thickness were measured in the three $D$. macropodum trees located on the Sunchon University campus. The degree of rolling was calculated with the distance (Df) between the leaf edges at freezing temperature and the distance (Dc) between the leaf edges at room temperature or when roll-

Table 1. General physical overview of the plant materials

\begin{tabular}{|c|c|c|c|c|}
\hline $\begin{array}{c}\text { Plant material } \\
\text { of } D . \text { macropodum }\end{array}$ & No. 1 & No. 2 & No. 3 & No. 4 \\
\hline \multirow{2}{*}{ Location (GPS) } & 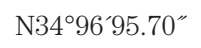 & N34ㅇํ의 $95.99^{\prime \prime}$ & 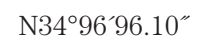 & N350ㅇ1․ \\
\hline & $\mathrm{E} 127^{\circ} 48^{\prime} 23.57$ & $\mathrm{E} 127^{\circ} 48^{\prime} 22.63^{\prime \prime}$ & $\mathrm{E} 127^{\circ} 48^{\prime} 21.80^{\prime \prime}$ & $\mathrm{E} 127^{\circ} 50^{\prime} 75.70^{\prime \prime}$ \\
\hline Tree height (m) & 2.7 & 3.0 & 3.0 & 7.5 \\
\hline Slope $\left({ }^{\circ}\right)$ & 1 & 2 & 1 & 5 \\
\hline Canopy openness $(\%)^{\dagger}$ & 37.5 & 20.3 & 15.0 & 58.5 \\
\hline Relative PPFD (\%) ${ }^{\dagger}$ & 40.5 & 20.7 & 15.3 & 83.2 \\
\hline
\end{tabular}

': Canopy openness and PPFD were estimated from hemispherical photographs taken at the top of individual trees. Gap Light Analyzer software (Frazer et al., 1999) was used to calculate the relative PPFD. 
ing did not occur (Nilsen et al., 2014). That is, the rolling ratio (\%) was calculated as (1 - Df / Dc) $\times 100$, which was $0 \%$ when the leaf rolling did not occur and $100 \%$ when the leaf edges overlapped. The degree of drooping was measured by the drooping angle of the leaf with respect to the horizontal line. On December 12, 2014, during the winter when the temperature dropped to freezing, the three $D$. macropodum trees on the Sunchon University campus were examined. From 6:00 am to 14:00 pm, the leaves were examined every hour, during which the temperature rose from $-8^{\circ} \mathrm{C}$ to $-4^{\circ} \mathrm{C}$. It was dark at 6:00 am, and the PPFD was measured at $2 \mu \mathrm{mol} \mathrm{m} \mathrm{m}^{-2} \mathrm{~s}^{-1}$ As it became brighter, the PPFD increased and rose to $120 \mu \mathrm{mol} \mathrm{m} \mathrm{m}^{-2} \mathrm{~s}^{-1}$ at around 14:00 pm, when it was cloudy. The relative humidity was 40-60\%, which was dry. The temperature was measured at 1-minute intervals using a HOBOware Pro (BHW-PC, Onset Computer). Immediately after five leaves were collected from each of the D. macropodum trees every hour, the weight of the fresh leaves was measured. Then, the leaves were dried in an oven dryer at $75^{\circ} \mathrm{C}$ for 24 hours, and the dry weight of the leaves was measured to calculate the wet weight. The leaf area was estimated using a leaf area measurement program by scanning the leaves with an ordinary scanner. The moisture content per area was obtained using this data. The leaf thickness was measured in the same manner as described above.

\section{Statistical analysis}

In order to analyze the statistical difference in the measurement data by period, one-way ANOVA and a Duncan test were performed at the $5 \%$ significance level for the leaf number, leaf area, leaf thickness, LMA, shoot length and SPAD value. The statistical differences in the moisture content per area and the leaf thickness with the temperature changes during each period were also analyzed in the same manner. IBM SPSS Statistics (ver. 21) was used for this statistical analysis.

\section{RESULTS AND DISCUSSION}

\section{Leaf phenology characteristics of Daphniphyllum macropodum}

In February and March 2014, the number of leaves that had emerged the previous year (1-year-old) was 15-16 per branch. In April 2014, there were 15-16 young leaves (current year), and the number of leaves did not differ from that of the 1-year-old leaves. As the young leaves began to emerge during the present year (2014), the 1-year-old leaves began to fall, and the number of 1 -year-old leaves decreased. When new leaves of $D$. macropodum emerge, the 1-year-old leaves tend to fall immediately. However, as shown in Fig. 1, even when the young leaves emerged in April 2014, the 1-year-old leaves remained on the branch for a considerable length of time. Moreover, the number of leaves varied greatly in the individual trees after April 2014. Kikuzawa (1989) reported that while $D$. teijsmannii below a gap area in a forest had only 2-year-old leaves on the branches, 4to 5-year-old leaves remained on the branches of the trees located on the forest floor. Leaf longevity is inversely proportional to the rate of photosynthesis (Chabot and Hicks, 1982), and even in the same species, the longevity of a leaf with a high photosynthesis rate tends to be shorter (Reich et al., 2004). In the present study, it appears that the light intensity applied to the individual trees varied, which led to the large variation in leaf longevity. Depending on the individual trees, leaf longevity is estimated to be about 360-510 days (12-17 months). Compared to the leaf longevity of 902-1850 days for Camellia japonica, 1163 days for Quercus glauca and 523-817 days for Castanopsis sieboldii, D. macropodum has short leaf longevity.

Nitta and Ohsawa (1997) investigated the leaf longevity of 11 evergreen broad-leaved species growing in Chiba Prefecture, Japan. In most species, leaves that had emerged in the spring fell from the spring to summer in the following year. In the spring, unfolding and defoliation often appeared at the same time. This could be a means to avoid self-shading. The LMA of $D$. macropodum was $148.1 \mathrm{~g} / \mathrm{m}^{2}$, which was similar to those of Camellia japonica (142) and Quercus glauca (139), and the leaves of $D$. macropodum were much thicker than those of deciduous broad-leaved Fagus engleriana (82) and Acer pictum subsp. mono (22). Similarly, the leaves of evergreen broad-leaved species are so thick that the photosynthesis rate of 1-year-old leaves is inevitably reduced due to the shading by new leaves. Considering that the leaves of $D$. macropodum, in particular, unfold in a flush, it is economically advantageous to reabsorb nutrients from the old leaves and feed the nutrients to young leaves. The falling leaves are a nutrient source, and the newly emerging leaves become the sink (Nitta and Ohsawa, 1997). Meanwhile, to avoid self-shading, there are spatial and temporal difference means (Kikuzawa, 2005). As shown in Fig. 2B, when the young leaves emerged in April, the leaf-bearing shoots grew rapidly within a short period. This rapid growth may be a strategy for minimizing self-shading by spread-

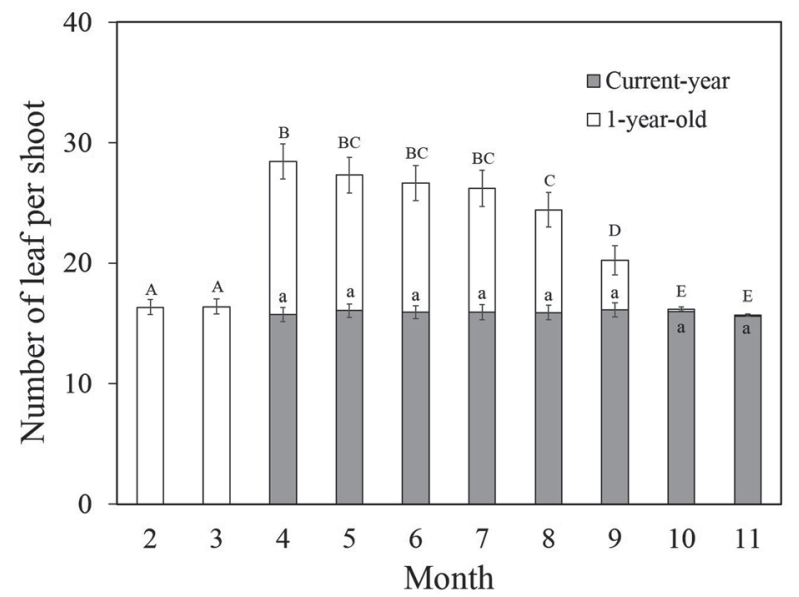

Fig. 1. Seasonal changes in the number of leaves per shoot of Daphniphyllum macropodum trees. Different letters (a, A-E) above the columns indicate statistical differences at the $5 \%$ level by Duncan's multiple range test. The error bars indicate standard error. 
ing the spacing between the leaves that unfold at the same time.

There were no statistically significant differences in the leaf area and the shoot length of the D. macropodum trees by period (Fig. 2A, 2B). Young leaves and shoots began to grow in early April and grew almost fully within a month. There were no statistically significant changes after the end of April (the measurement date). However, there was a statistically significant difference in the leaf thickness from April to July 2014. The leaves were thin at the beginning of the emergence of new leaves, but they became thicker and thicker until July, when the leaf thickness reached the maximum value (Fig. 2C). The LMA also showed a similar pattern as the leaf thickness. The LMA and the leaf thickness tend to increase with the maturation of the leaf tissue compared with the early stage of development. Given that there is no reason for the LMA and the leaf thickness to increase and then decrease again, the August data appears to be measurement errors. The SPAD value, which indirectly indicates the chlorophyll content, also increased from April until the SPAD reached the maximum value in September, showing a similar pattern as the leaf thickness. The SPAD value of the 1 -year-old leaves was maintained at 60 until April but then decreased rapidly, and this pattern was similar to the changes in the number of leaves. This pattern can be explained by the fact that the leaves had reached the end of their lifespan due to aging.

The leaf area and the shoot length matured early within 1-2 months after the leaves unfolded, but it took time for the LMA, leaf thickness and chlorophyll content to reach the maximum values. The number of days required until the maximum photosynthesis rate is reached after the leaf surface is maximized is called the maturation period. Miyazawa et al.'s (1998) study of the development of evergreen broad-leaved leaves reported a direct correlation between the maturation period and the LMA. That is, it takes time for the leaf tissue to mature. The temporal difference between the period required for the completion of the leaf surface area and the period required for the maturation of the leaf structure is called delayed greening. This difference could play a role in the adaption of the leaves to the light conditions (Kikuzawa, 2005). Kursar and Coley (1992) suggested that this difference is significant for avoiding predators. Among the various methods for avoiding feeding damage from predators, making the leaves too rough and tough to eat is the most effective strategy. However, maturing leaves in the early stage may have a high opportunity cost. In other words, because the feeding damage caused by predators is mainly focused on young leaves, much of the plant's nitrogen could be purged by predators during the early maturing stage. In addition, even if the leaves mature early at low light levels, then the production yield of the assimilated materials will not be large. Furthermore, the leaves and bark extracts of D. macropodum have been used as an insect repellent for a long time, but the plant is also known to be toxic; excessive intake causes dyspnea (Kobayashi and Morita, 2003). The leaves of $D$. macropodum contain highly
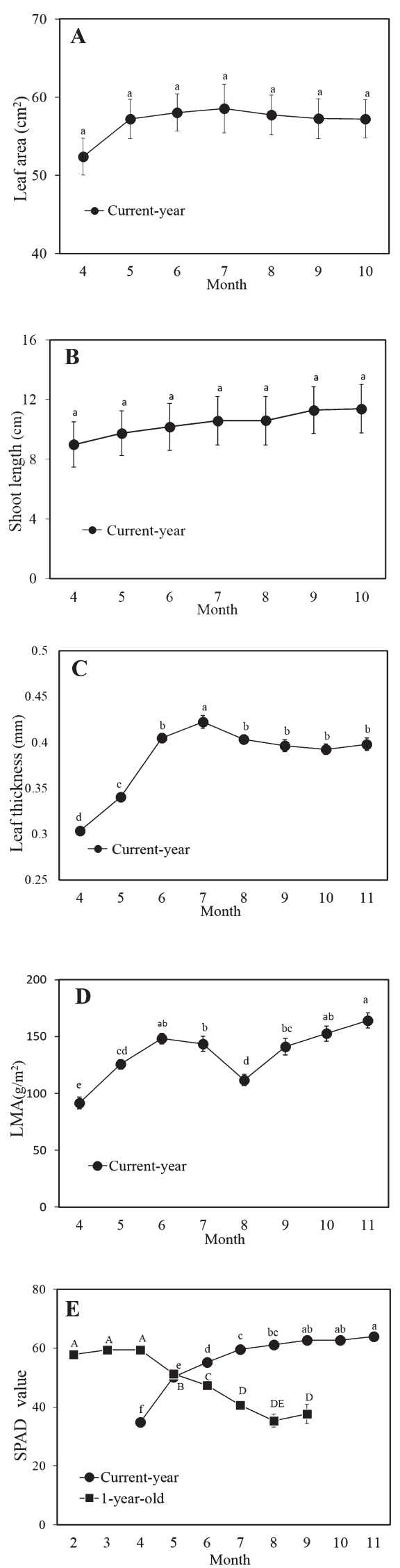

Fig. 2. Seasonal changes in the leaf area (A), shoot length (B), leaf thickness (C), LMA (D) and SPAD value (E) of Daphniphyllum macropodum trees. Different letters (a-f, A-D) within a graph indicate statistical differences at the $5 \%$ level by Duncan's multiple range test. 


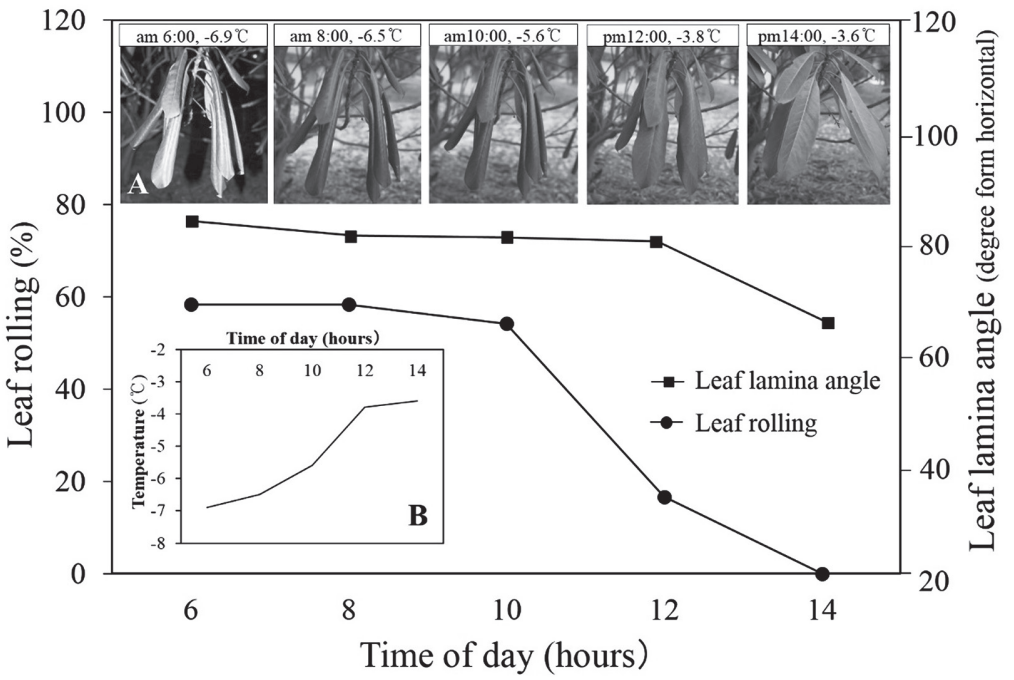

Fig. 3. Changes in the rolling and drooping of the Daphniphyllum macropodum leaves during a typical daily cycle. The photographs (A) and graphs (B) in this figure show the changes in the leaves and temperature from 6:00 am to 14:00 pm.

concentrated alkaloids, which act as chemicals to protect the leaves from insects (Kikuzawa, 2005). During the present study, no leaf fell due to feeding damage caused by insects, and there were no signs of insect pitting. As D. macropodum is fully equipped with a chemical defense system, physically defending the leaves by maturing them early is not necessary.

Leaf longevity and the LMA are directly proportional; thus, the leaf longevity of evergreen broad-leaved trees is longer than that of deciduous broad-leaved trees (Kikuzawa, 2005). Based on this relationship and considering that $D$. macropodum leaves are thick, the tree's leaf longevity should be long. However, it was shorter than that of evergreen broad-leaved species that grow in warm-temperature zones, in spite of the large variation in leaf longevity depending on light intensity. New leaves of $D$. macropodum unfold in a flush in the spring, resulting in a self-shading effect; thus, reabsorbing nutrients from old leaves and dropping the leaves early seems to be more favorable in terms of the plant's carbon economy. That is, as the maintenance cost of 1year-old leaves is higher than the production yield of assimilated materials (profit) due to their aging, the leaves should be dropped early.

\section{Thermonastic leaf movement of Daphniphyllum macropodum}

The temperature at 6:00 am on the December 12, 2014 of measurement was $-6.9^{\circ} \mathrm{C}$ and gradually increased with time, rising to $-3.6^{\circ} \mathrm{C}$ at $14: 00 \mathrm{pm}$ (Fig. $3 \mathrm{~A}$ ). At the beginning of the measurement, rolling and drooping appeared and then disappeared by 14:00 pm (Fig. 3). The changes in the degree of drooping between 6:00 am and 14:00 pm were not as significant when measured at $15^{\circ} \mathrm{C}$. However, the changes in rolling were more dramatic (58\%). This is the same phenomenon as the thermonastic leaf movement that is well known to occur in
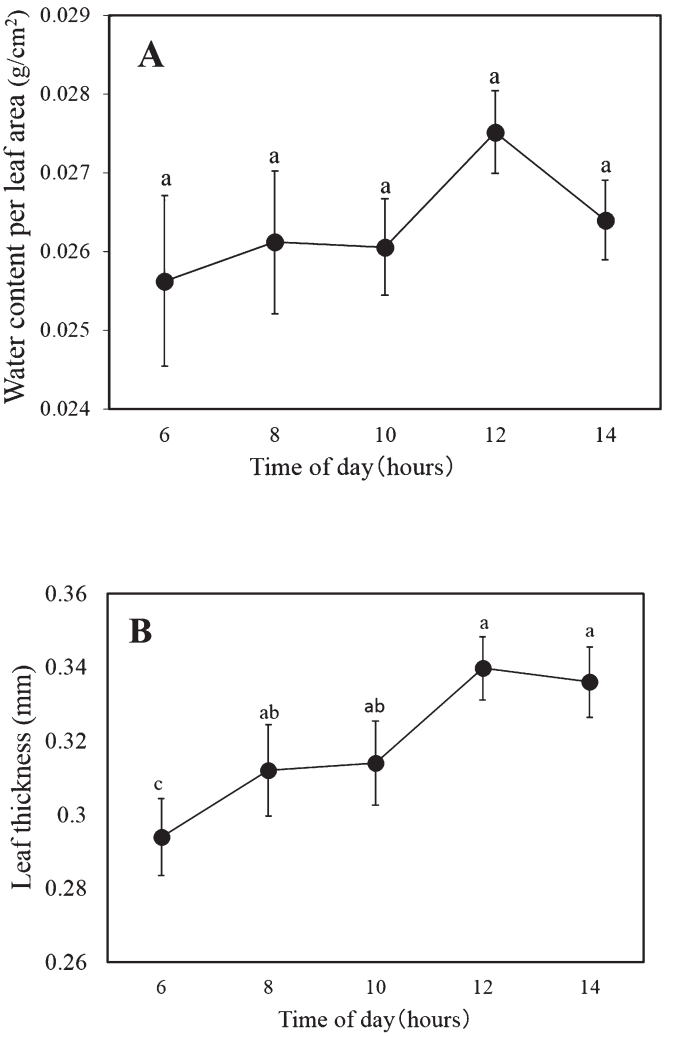

Fig. 4. Changes in the leaf thickness (A) and water content per area (B) according to the changes in the freezing temperature in the Daphniphyllum macropodum trees. The photographs (A) and graphs (B) in this figure show the changes in the leaves and temperature from 6:00 am to 14:00 $\mathrm{pm}$. Different letters $(\mathrm{a}-\mathrm{c})$ within a graph indicate statistical differences at the $5 \%$ level by Duncan's multiple range test. 
evergreen Rhododendron in winter (Nilsen et al., 2014). The leaf thickness measured at 12:00 and 14:00 pm (Fig. 4B) was statistically significantly thicker than that at 6:00 am. However, the moisture content per unit area (Fig. 4C) did not show any statistical difference over time.

The thermonastic leaf movement can be divided into two processes, drooping and rolling, according to the response dynamics of light intensity, leaf water potential and leaf temperature (Nilsen, 1987). Drooping depends on the osmotic potential of the petiole leaf that is affected by light intensity and temperature (Nilsen et al., 2014). Unlike drooping, rolling does not depend on light intensity and leaf water content. Rhododendron grow wild in the temperate zone, so when the plant's leaves fall in winter, the plant is exposed to high radiation and freezing temperatures through under the open water tubes, which are open during defoliation (Nilsen et al., 2014). In this state, as a way to resist the stress of photoinhibition and dehydration of the leaf, the osmotic potential of the petiole leaf is lowered, and the angle of the leaf lamia becomes lower than that of a horizontal line. Because the D. macropodum trees in this study were located in a half-shadow area, they were not exposed to radiation, and it was cloudy on the day of measurement. Therefore, the purpose of the changes in the leaf angle of the $D$. macropodum trees would have been to prevent leaf dehydration at the freezing temperature rather than to protect the photosynthesis system. However, given that D. macropodum is an arborescent, shade-adaptive plant that grows mainly in the lower layer of evergreen broadleaved forests, the plant may be susceptible to photoinhibition under a high radiation condition. Therefore, it is believed that thermonastic leaf movement occurs as an adaptive response to this stress.

Meanwhile, rolling of $D$. macropodum leaves was thought to be caused by the decrease in water content, but the moisture weight per leaf area did not change with a change in the freezing temperature (below $0^{\circ} \mathrm{C}$ ). This phenomenon is likely to be different from dehydration in which the moisture of the leaf escapes at the wilting point. In contrast, a statistically significant change was observed in the leaf thickness. Water movement patterns between plant tissues have been identified as a major cause of leaf movement (Uehlein and Kaldenhoff, 2008). Extracellular water freezes faster than intracellular water due to the lower sugar content. When extracellular water freezes, the water potential there is lowered, and the water in the cell moves to the extracellular space. Nilsen et al. (2014) argued that in order for rolling to occur at freezing temperatures, water must travel from the abaxial surface (backside) of the leaf to the adaxial surface (front side) to expand the adaxial region while compressing the abaxial region. In addition, there is anatomical evidence that the proportion of the abaxial region (palisade cells) in the leaves of plants that grow in temperate regions is usually higher with a large open space in the abaxial region (spongy mesophyll). Therefore, it is reasonable to assume that the spongy tissue area should be compressed during the thermal leaf rolling process (Nilsen et al., 2014). As the leaves of $D$. macropodum begin to freeze, the leaf thickness appears to become thinner as the water gathers in one direction during the expansion and compression processes within the tissue due to the water movement.

Nilsen and Tolbert (1993) showed a positive correlation between the leaf rolling rate and cold tolerance in a study of 32 species of Rhododendron in different habitats. In addition, the authors concluded that the thermonastic leaf movement of Rhododendron is a mechanism for preventing water loss during winter and for protecting the photosynthesis system from damage in extreme light conditions during winter. The most important role of this leaf movement is to provide resistance to winter environmental conditions (Nilsen et al., 2014). D. macropodum is distributed in warm-temperature zones and subtropical regions. What is unusual is that colonies of $D$. macropodum trees remain in the inland mountains of Naejangsan National Park, a temperate region of the Korean peninsula. The natural habitats of individual tree species are affected by temperature, which is particularly limited by the lowest temperature in winter. Thermonastic leaf movement of $D$. macropodum is likely to account for its ability to grow wild even in the temperate zone, although this plant species normally grows in warm-temperature or subtropical zones.

\section{CONCLUSIONS}

In April, as the young leaves began to unfold in a flush, the leaves that had emerged the previous year began to fall. The leaf longevity of $D$. macropodum was about 12-17 months with a large individual variation depending on the light intensity. In spring, unfolding and defoliation of the leaves occurred almost simultaneously, which is a means of avoiding self-shading. D. macropodum leaves are thick and wide; thus, 1-year-old leaves block the light from young leaves, reducing their photosynthesis rate. Therefore, it is not necessary to keep old leaves on the branch for a long time. The leaf longevity of $D$. macropodum is determined by the production yield of the assimilates (profit) and the maintenance cost. This is called the plant's carbon economy.

The D. macropodum leaves showed thermonastic leaf movement, such as drooping and rolling at freezing temperatures in winter. These phenomena are believed to be a reaction to the freezing temperature to prevent excessive water loss in winter. There was no change in the moisture content of the leaves due to the thermonastic leaf movement, but the leaf thickness tended to be thinner. This movement has a different mechanism from the dehydration phenomenon in which the moisture of the leaves escapes at the wilting point. At freezing temperatures, the water inside the cells migrates out of the cell and gathers at the extracellular area of the adaxial region (palisade cells) to expand the region while compressing the abaxial region (spongy mesophyll), which results in rolling. The leaf thickness decreases as moisture accumulates in one direction during these expansion and compression processes due to the water movement 
between the leaf tissues.

\section{AUTHOR CONTRIBUTIONS}

S. G. Park designed the study, performed the histological experiments, analyzed the data and wrote the paper. M. Matsumoto supervised the work, wrote the paper. All authors assisted in editing of the manuscript and approved the final version.

\section{ACKNOWLEDGEMENTS}

This research was supported by Basic Science Research Program through the National Research Foundation of Korea (NRF) funded by the Ministry of Science, ICT and Future Planning (No. NRF2012R1A1A1010483)

\section{REFERENCES}

Chabot, B. F. and D. J. Hicks 1982 The ecology of leaf life spans. Annual Review of Ecology and Systematics, 13: 229-259

Frazer, G. W., C. D. Canham and K. P. Lertzman 1999 Gap Light Analyzer (GLA), Version 2.0: Imaging software to extract canopy structure and gap light transmission indices from true-colour fisheye photographs, users manual and program documentation. New York, p. 36

Fukuda, Y. 1932 Hygronastic curling and uncurling movement of the leaves of Rhododendron micranthum Turcz. with respect to temperature and resistance to cold. Japanese Journal of Botany, 6: 191-224

Kikuzawa, K. 1989 Ecology and evolution of phenological pattern, leaf longevity and leaf habit. Evolutionary Trends in Plants,
3: $105-110$

Kikuzawa, K. 2005 Ecology of Leaf Longevity -from individual leaves to ecosystems-. Kyoritsu Shuppan, p. 212 (in Japanese)

Kobayashi, J and H. Morita 2003 Unique ring systems and biogenetic path of Daphniphyllum alkaloids. Journal of Synthetic Organic Chemistry, Japan, 61: 35-44

Kursar, T. A. and P. D. Coley 1992 Delayed greening in tropical leaves : an antiherbivore defense? Biotropica, 24: 256-262

Miyazawa, S., S. Satomi and I. Terashima 1998 Slow leaf development of evergreen broad-leaved tree species in Japanese warm temperate forests. Annals of Botany, 82: 859-869

Nilsen, E. T. 1985 Seasonal and diurnal leaf movements of Rhododendron maximum in contrasting irradiance environments. Oecologia, 65: 296-302

Nilsen, E. T. and A. Tolbert 1993 Does winter leaf curling confer cold stress tolerance in Rhododendron?. Joumal American Rhododendron Society, 47: 98-104

Nilsen, E. T. 1987 Influence of water relations and temperature on leaf movements of Rhododendron species. Plant Physiology, 83: 607-612.

Nilsen, E. T., R. Arorab, and M. Upmanyuc 2014 Thermonastic leaf movements in Rhododendron during freeze. thaw events: Patterns, functional significances, and causes. Environmental and Experimental Botany, 106: 34-43

Nitta, I. and M. Ohsawa 1997 Leaf dynamics and shoot phenology of eleven warm-temperate evergreen broad-leaved trees near their northen limit in central Japan. Plant Ecology, 130: 71-88

Park, J. G., J. B. An, S. B. Park, G. C. Choo and B. G. Kim 2015 Vegetation properties of Daphniphyllum macropodum natural habitats in South Korea. Journal of Agriculture \& Life Science, 49: 117-133 (in Korean with English abstracts)

Reich, P. B., C. Uhl, M. B. Walters, L. Prugh and D. Ellsworth 2004 Leaf demography and phenology in Amazonian rain forest : a census of 40000 leaves of 23 tree species. Ecological Monographs, 74: 3-23

Uehlein, N. and R. Kaldenhoff 2008 Aquaporins and plant leaf movements. Annals of Botany, 101: 1-4 